\title{
Plan de Cuidado Enfermero para Paciente Positivo a SARS-CoV-2 en autoaislamiento y sintomatología estable
}

\section{SARS-CoV-2 Positive Patient Nurse Care Plan in self-insulating and stable symptomatology}

\author{
Rocío B. Mayorga-Ponce ${ }^{a}$, Perla E. Osorio-Solis ${ }^{b}$, Abigail Martínez-Alamilla $^{c}$, Daniela Salazar- \\ Valdez $^{d}$
}

\begin{abstract}
:
This work concerns the current topic of the SARS-CoV-2 pandemic, who according to WHO "is the most recently discovered infectious disease caused by coronavirus. This new virus and disease became unknown before the outbreak began in Wuhan, China, in December 2019. COVID-19 is now a pandemic affecting many countries globally." Importantly, coronaviruses (CoVs) are a large family of respiratory viruses that can cause diseases ranging from the common cold to Middle East respiratory syndrome (MERS) and severe acute respiratory syndrome (SARS), both of zoonotic origin and induce a fatal infection of the lower respiratory tract, as well as extrapulmonary manifestations. The new $\mathrm{CoV}$, officially designated as SARS coronavirus 2 (SARS-CoV-2), was first identified in Wuhan by the Chinese Center for Disease Control and Prevention (CDC). It is of general character and importance to make the particularities of SARs-Cov-2 aware as well as relevant to specific nursing personnel make use of a Nurse Care Process that is useful in the development and planning of the correct care to be carried out in patients presenting the pathology.
\end{abstract}

Keywords:

Pandemic, SARS-CoV-2, Coronavirus, Respiratory Viruses, Nursing

\section{Resumen:}

El presente trabajo de investigación se refiere al tema actual de la pandemia por SARS-CoV-2, que según la OMS “es la enfermedad infecciosa causada por el coronavirus descubierto más recientemente. Este nuevo virus y enfermedad se desconocían antes de que comenzara el brote en Wuhan, China, en diciembre de 2019. COVID-19 es ahora una pandemia que afecta a muchos países a nivel mundial". Es importante decir que, los coronavirus $(\mathrm{CoV})$ son una gran familia de virus respiratorios que pueden causar enfermedades que van desde el resfriado común hasta el síndrome respiratorio de Oriente Medio (MERS) y el síndrome respiratorio agudo severo (SARS), ambos de origen zoonótico e inducen una infección mortal del tracto respiratorio inferior, así como manifestaciones extrapulmonares. El nuevo CoV, designado oficialmente como el coronavirus 2 del SARS (SARS-CoV-2) fue identificado por primera vez en Wuhan por el Centro Chino para el Control y la Prevención de Enfermedades (CDC). Es de carácter e importancia general hacer del conocimiento las particularidades del SARs-Cov-2 así como también es relevante para el personal sanitario, en específico de enfermería hacer uso de un Proceso de Atención Enfermero que sea útil en el desarrollo y planificación de los correctos cuidados que se han de llevar a cabo en pacientes que presenten la patología.

\section{Palabras Clave:}

Pandemia, SARS-CoV-2, Coronavirus, Virus Respiratorios, Enfermería.

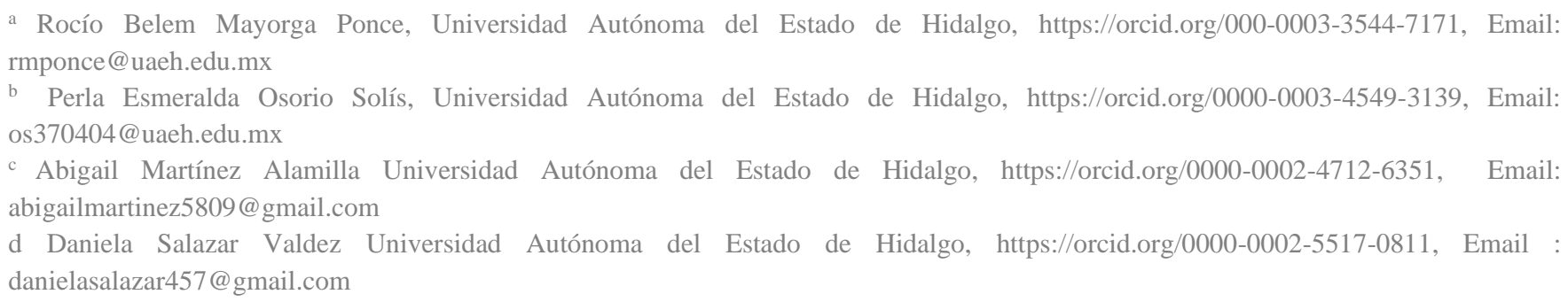




\section{Introducción}

Durante los meses que han transcurrido desde el inicio del año 2020, diversas problemáticas a nivel global han afectado al sector económico en sus múltiples variantes, sin embargo, la causa del estrago mayor a nivel global ha sido la presencia del nuevo virus SARS-CoV-2 mundialmente conocido como Coronavirus que según la $\mathrm{OMS}^{1}$ "es la enfermedad infecciosa causada por el coronavirus descubierto más recientemente. Este nuevo virus y enfermedad se desconocían antes de que comenzara el brote en Wuhan, China, en diciembre de 2019. COVID-19 es ahora una pandemia que afecta a muchos países a nivel mundial".

Hasta el momento, las cifras oficiales ascienden a más de 24.021.218 casos confirmados de COVID-19, incluyendo 821.462 muertes reportadas por la Organización Mundial de la Salud a nivel mundial. En lo que respecta a México, las cifras oficiales indican un total de 568.621 casos confirmados con 61.450 muertes reportadas. ${ }^{1}$

El resultado de esta pandemia ha incurrido directamente sobre el personal sanitario, potencialmente médicos y enfermeras; de aquí radica la importancia de planear correctamente los cuidados que se brindan a los pacientes afectados por COVID-19. Es por ello que el desarrollo de una Proceso de Atención Enfermero aplicado a un paciente positivo a tal virus es de trascendencia en la investigación futura debido a las vertientes particulares de cada individuo.

El proceso de enfermería es un proceso sistemático de pensamiento crítico el cual promueve un nivel competente de cuidados, representa una resolución deliberada de cuidados y engloba todas las acciones importantes que realizan las enfermeras por lo cual establece la base para la toma de decisiones. ${ }^{[2]}$

\section{Objetivos}

General

Contribuir al análisis de la situación de orden sanitario coadyuvando en la proposición de cuidados e intervenciones de enfermería para COVID-19

\section{Específicos}

Generar un plan de cuidados de enfermería aplicado a COVID-19 en paciente aislado en su hogar.

Analizar el comportamiento del virus por medio de los signos y síntomas presentados.

Implementar el uso de estrategias e intervenciones que encaminen al paciente a la recuperación física y psicológica y que igualmente garanticen la bioseguridad del personal de enfermería.

Identificar los patrones funcionales alterados en el paciente con COVID-19

\section{Metodología}

El estudio a realizar será de tipo cualitativo, ya que según Sampieriं3; el enfoque se basa en métodos de recolección de datos no estandarizados ni completamente predeterminados. No se efectúa una medición numérica, por lo cual el análisis no es estadístico. La recolección de los datos consiste en obtener las perspectivas y puntos de vista de los participantes (sus emociones, prioridades, experiencias, significados y otros aspectos subjetivos).

\section{Historia natural de Sars-COV-2}

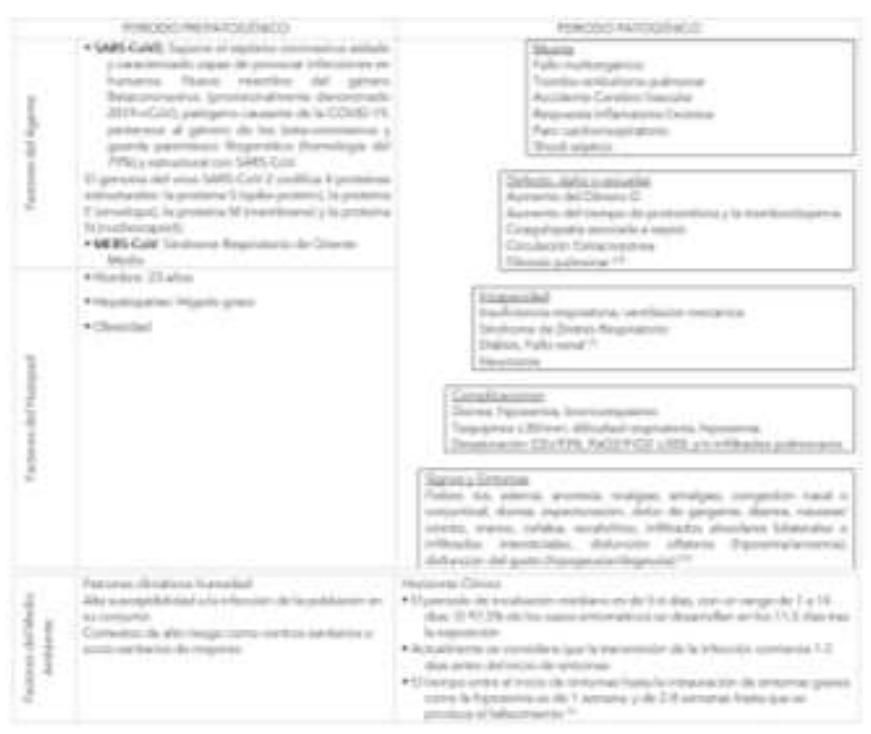

\section{Niveles de prevención de Leavell y Clark}

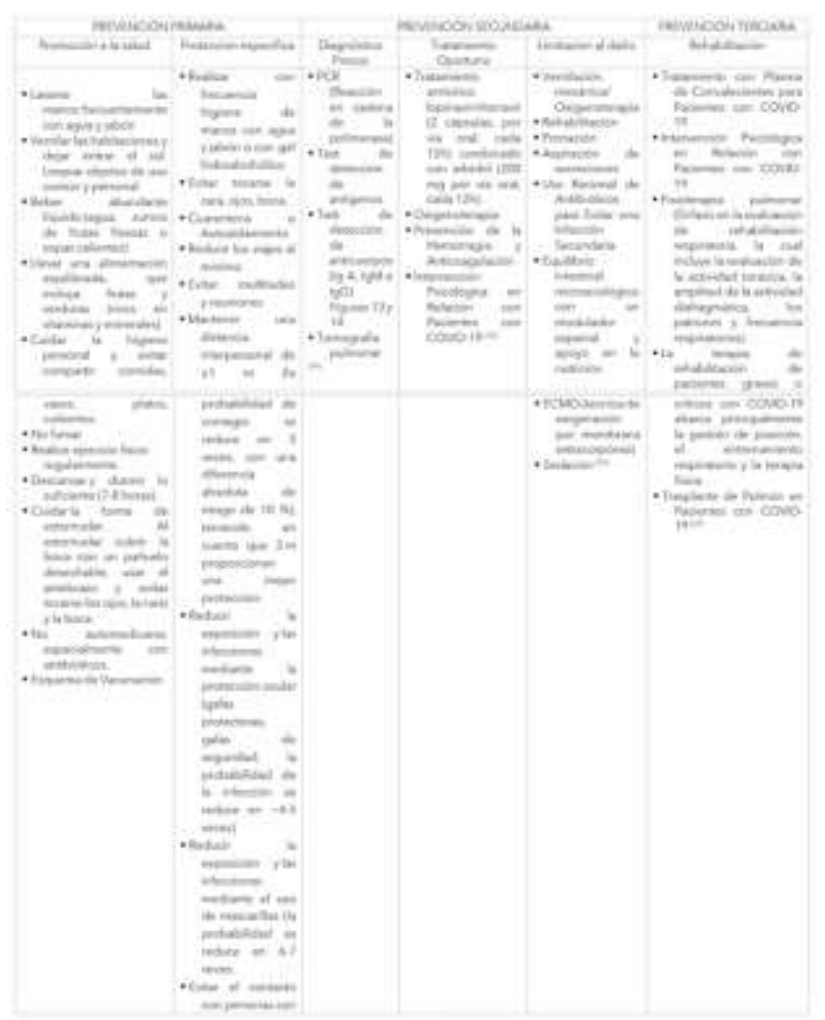




\section{Razonamiento diagnóstico ${ }^{4}$}
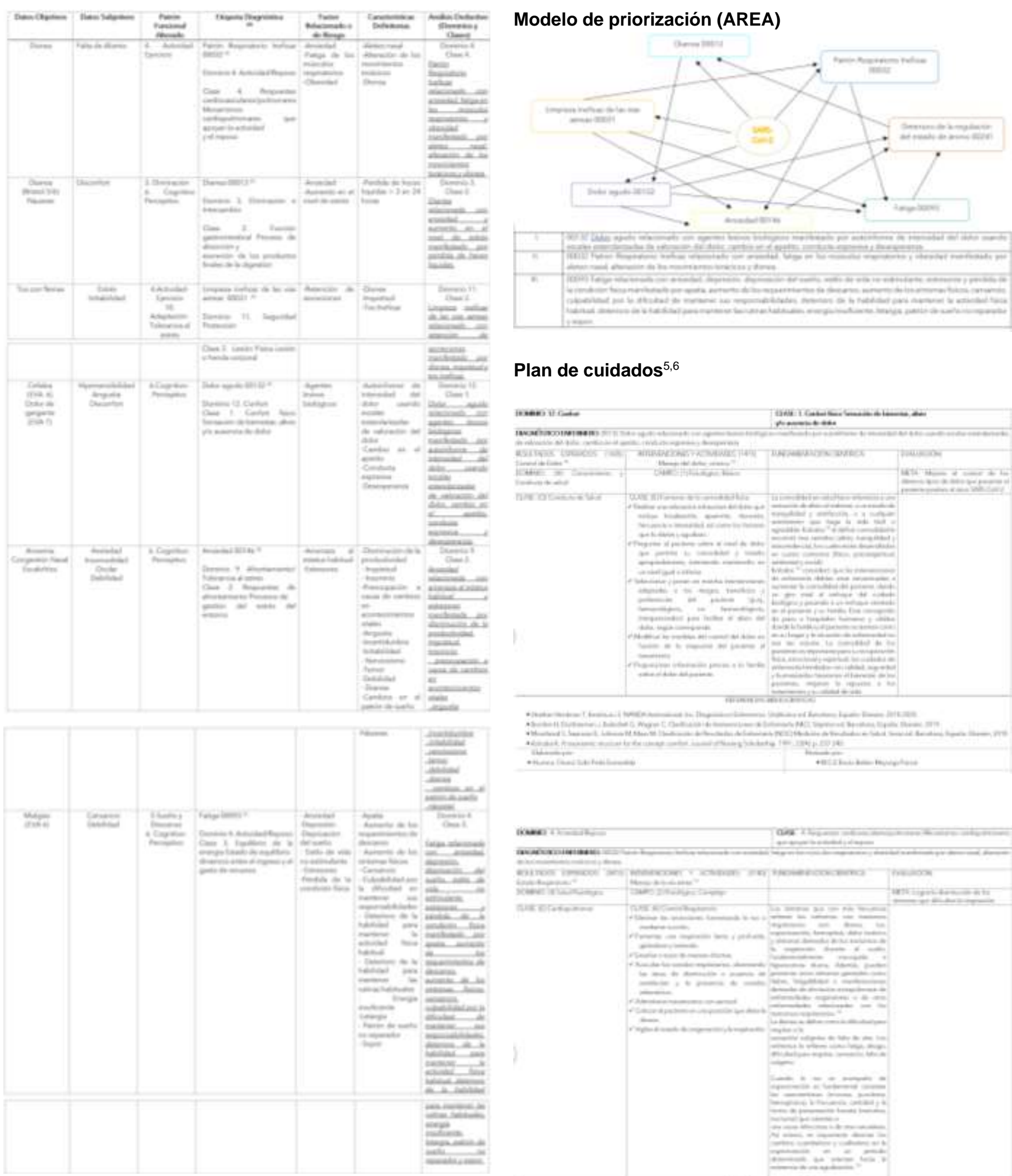

\section{Plan de cuidados ${ }^{5,6}$}
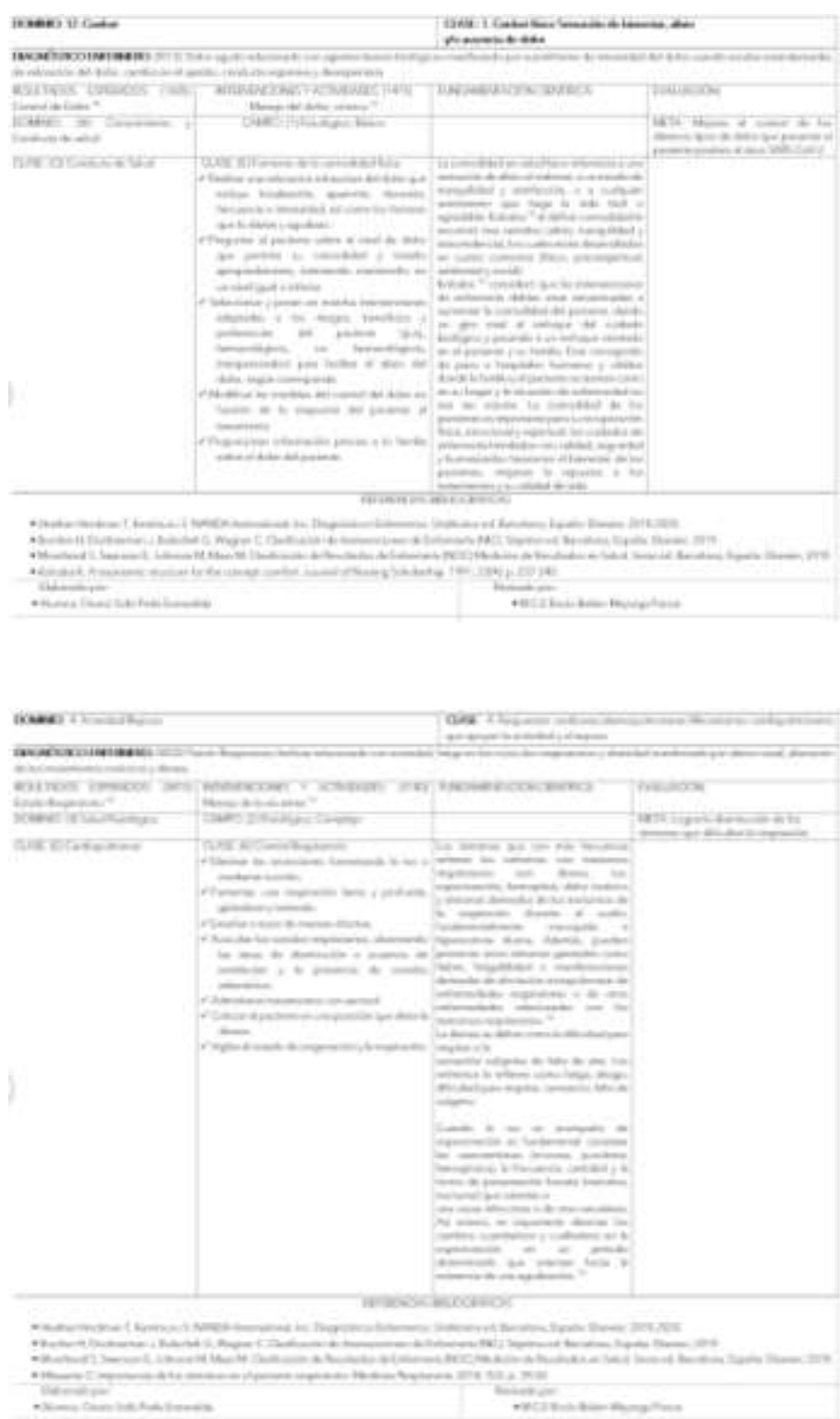


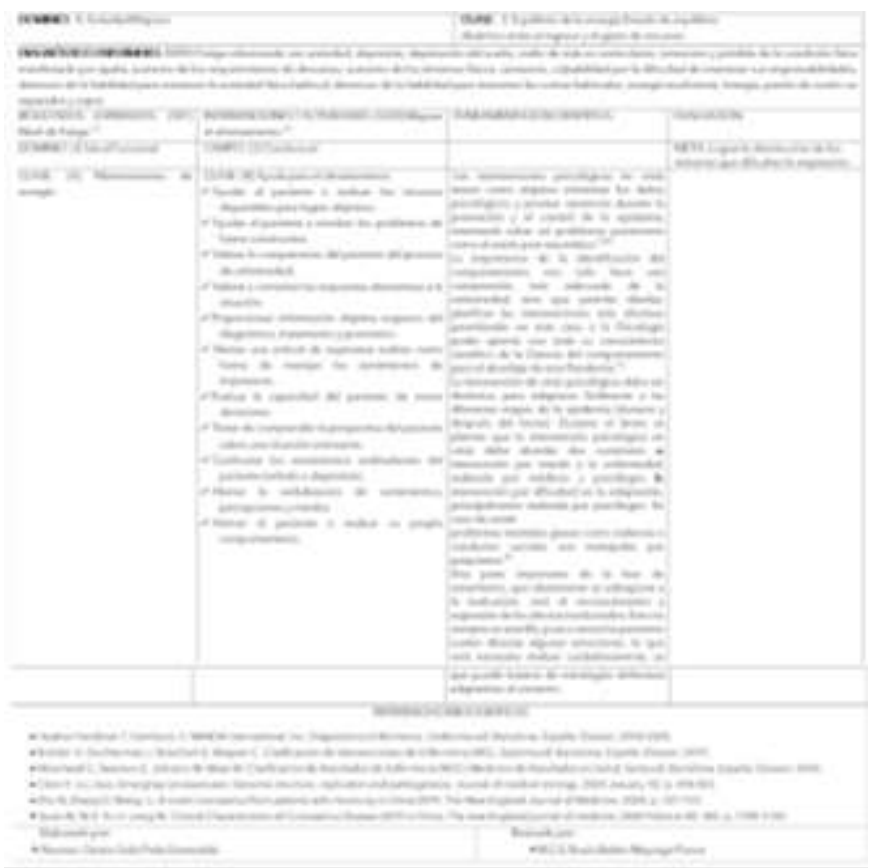

\section{Plan de alta en nemotecnia (CUIDARME)}

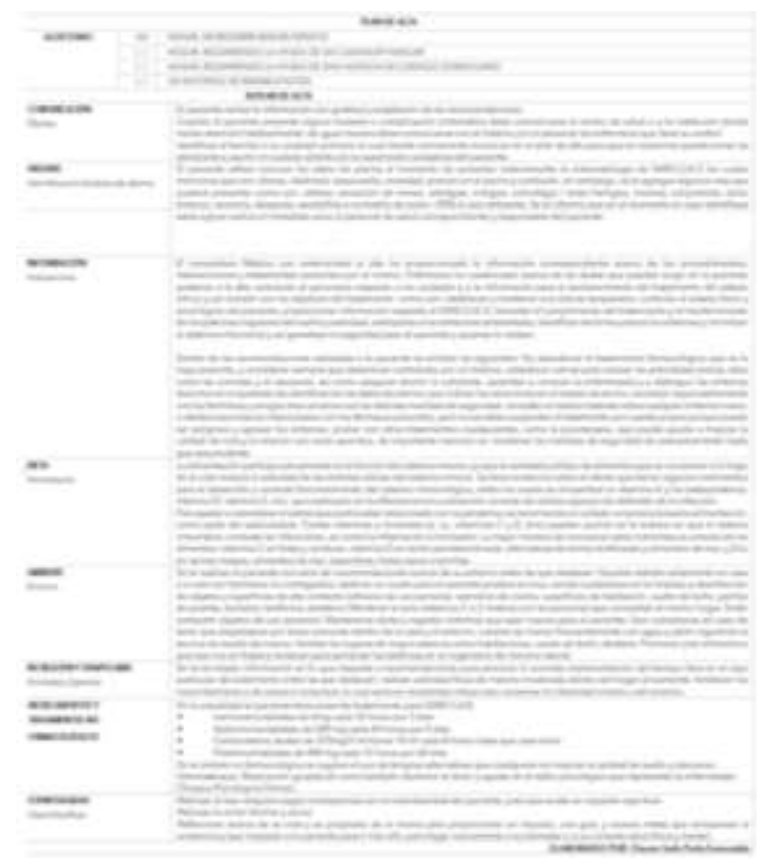

\section{Conclusiones}

Para el personal enfermero resulta un completo reto cada paciente que resulta positivo a SARS-CoV-2, debido a que es una enfermedad totalmente nueva que goza de complejidad, en la actualidad sigue estudiándose por los grandes científicos y una parte fundamental para las investigaciones son las intervenciones enfermeras.

La investigación enfermera es de suma importancia para las futuras generaciones, así como ha sido de trascendencia mundial el legado enfermero que es el uso de las taxonomías conformadas por las sucesoras en enfermería.

La pandemia ha puesto a prueba el sistema de salud nacional e internacional y ha exigido así a los equipos sanitarios un alto grado de compromiso y entrega para contener la enfermedad, en esto las enfermeras han tenido un gran protagonismo, liderando lo que se ha dado en llamar la "primera línea" de atención a las personas que acuden a los centros asistenciales en busca de ayuda.

"La observación indica cómo está el paciente; la reflexión indica qué hay que hacer; la destreza práctica indica cómo hay que hacerlo. La formación y la experiencia son necesarias para saber cómo observar y qué observar; cómo pensar y qué pensar" Florence Nightingale, 188

\section{Referencias}

[1] Dilla T, Valladares A, Lizán L, Sacristán JA. Adherencia y persistencia terapéutica: causas, consecuencias y estrategias de mejora. Aten. Primaria 2009; 41(6): 342-48.

[2] Silva G, Galeano E, Correa J. Compliance with the treatment. Acta Médica Colombiana 2005; 30(4): 268-73.

[3] Viesca TC. Paternalismo médico y consentimiento informado. En: Márquez-Romero R, Rocha- Cacho WV, editors. Consentimiento informado. Fundamentos y problemas de su aplicación práctica. 1st ed. México: UNAM; 2017: 1-22.

[4] Grady P, Lucio-Gough L. El automanejo de las enfermedades crónicas: un método integral de atención. Panam. J. Public. Health. 2015; 35(9): 187-194.

[5] Cañete-Villafranca R, Guilhem D, Brito-Pérez K. Paternalismo médico. Rev. Med. Elect. 2013; 35(2): 144-152.

[6] Caballo C, Pascual A. Entrenamiento en habilidades de automanejo en personas con enfermedades crónicas: un estudio cuasi-experimental. En: Universidad de Salamanca, editor. IX Jornadas Científicas Internacionales de investigación sobre personas con discapacidad Salamanca; INICO; 2012: 1-12.

[7] Millaruelo-Trillo JM. Importancia de la implicación del paciente en e autocontrol de su enfermedad: paciente experto. Importancia de las nuevas tecnologías como soporte al paciente autónomo. Aten. Primaria 2010; 42(1): 41-47.

[8] Bonal-Ruiz R, Cascaret-Soto X. Reflexión y debate ¿Automanejo, autocuidado o autocontrol en enfermedades crónicas? Acercamiento a su análisis e interpretación. MEDISAN. 2009; 13(1): 1-10.

[9] Lorig K, Ritter PL, Villa F, Piette JD. Spanish diabetes selfmanagement with and without automated telephone reinforcement. Diabetes Care 2008; 31(3): 408-14.

[10] Kidney Disease Improved Global Outcomes (KDIGO). KDIGO 2012 Clinical Practice Guideline for the Evaluation and Management of Chronic Kidney Disease. Off. J. Int. Soc. Nephrol. 2013; 3(1): 1-163.

Haga clic o pulse aquí para escribir texto. 